\title{
The Images of Chinese Traditional Colors and Cultural Preferences -Focus on the Movie Costumes of <The Last Emperor >-
}

\author{
Young Sam Kim - Yuh Sun Jun ${ }^{\dagger}$ \\ Dept. of Clothing \& Textiles, Chung-Ang University \\ Received October 26, 2010; Revised (December 17, 2010; December 24, 2010); Accepted December 28, 2010
}

\begin{abstract}
An authentic national spirit in media (particularly films), traditional images, and color preferences is expressed through movies that are melted in local traditions. This study suggests a direction regarding the characteristics for historical costumes by examining traditional color images and cultural preference in the Chinese film <The Last Emperor> (1987), a representative film that deals with Chinese history and traditions. This movie can illustrate the correlation between the temporal backgrounds and the costumes in the movie with the criteria of Eastern color systems. The results of this research are summarized as follows. First, the image of Chinese traditional colors represented in many parts of $<$ The last Emperor $>$ and the cultural preferences that underlies their works through the expression of traditional colors. The scenes of traditional costumes and colors express the visual embodiments of the costumes that reflect a specific status, ceremony, or ritual. Second, the traditional colors used in the movie are based on the Yin-Yang theory. Particularly, Red, Yellow, Black is mostly used for ordinary clothing. Third, there are some differences in the use of color arrangements, that change regarding the use of traditional colors according to images and situations that follow the intention of the director. Planning the color arrangements is considered an engaging connectivity between traditions and images in the movie and it is extended or reduced based on cultural preferences. Fourth, the increase and decrease of color arrangements is distinctively represented as the story of the movie proceeds.
\end{abstract}

Key words: Chinese traditional colors, Cultural preferences, The Last Emperor

\section{Introduction}

The unique characteristics of a country on media strives to cover and reflect all aspects of national culture and its preference. As Pieterse (2004) states, culture used to take the form of national difference in national character or identity. Particularly, the cultural preference and traditional image regarding colors closely relates artistic values in the media. In terms of analyzing one's cultures in media, it can be obtained their view points of preference, and even trends caused from traditional images as well as recognize cos-

† Corresponding author

E-mail: sunny1921@hanmail.net

This Research was supported by the Chung-Ang University Research Scholarship Grants in 2009. tumes' design and color which reflect a particular culture. With this point: costumes and its color on films generally reflect social and cultural atmospheres as well as the creative path of communication with the receiver, which signifies the prevailing cultural interaction the nation has. Through media, especially films, country's traditional images and color preference represents through their representative movies which are melted into their own tradition. Kim and Kim (2010) mentions color expression for stage is important to convey appropriate atmosphere of theatre for audience through general color images and psychological effect by stimulating associations about colors.

The purpose of this study tries to suggest a direction of future research in dress history by examining traditional color's images and cultural preference on 
Chinese film and figure out the correlation between the temporal backgrounds and the costumes in works, with the criteria of eastern color system mainly. In addition, this research is meaningful to compare the outcomes with Korean films and costumes for the future study. The film, < The Last Emperor> (1987) focused on this research, is the representative example that deals with the history and tradition in China. And the color expressions of the movie were also famous issue at the running period of movie ("When film", 2009). And the movie is world renowned film which won nine Academy Awards in every category, particularly costume award, in which it was nominated as well as it delineates the last dynasty of Chinese history.

\section{Literature Review}

As borders fade, the value and images of national identities becomes more influential. Culture is defined as the set of characteristics which distinguish one group from another (Pieterse, 2004). For example, when approaching China, many international people usually regard it as of the 'country of the dragon', or sometimes they are reminded of the red, the representative color of the country. In addition, Ma (1999) states it needs to try to rethink some of the popular theoretical perspectives and preference through their media studies. Therefore, when it comes to the role of media in China, authentic images and cultural preference melted into the colors of costumes in their media. Specifically, according to Chinese culture and precedent studies regarding traditional colors, dating back to the time of the Yellow Emperor, the five elements are fire, earth, wood, metal, and water has been important (Ho, 1986). The five elements are represented the five primer colors based Yin-Yang theory.

Corresponding to the five elements respectively are the five colors red, yellow, blue, white and black. Virtually, eastern color systems can be stated notional configuration in terms of the color arrangements comparing to western color system through an optical measurement and analytic assessment. In western color system, black and White takes the ancillary role which they just control brightness without any concept for primer colors. Reversely, in eastern color systems, black and White have equal position with the three kinds of primer colors. Thus, eastern color systems, that is the arrangements of five colors based Yin-Yang theory, allows to have one's own authentic attributes individually (Jo, 2010). Beyond this stage, the color arrangements of eastern color systems illustrate with direction and elements that Red for south, Yellow for center, Blue for east, White for west, and Black for north, and so forth (Fig. 1). In order to support visual aspects for understanding and limit its scope to five primer colors, the eastern color systems juxtapose with Munsell Hue Circle, I.R.I Hue and Tone 120 System. For instance, Red covers for R, Yellow covers for $Y$, Blue covers for $\mathrm{PB}$ and B, and so forth (Fig. 2). Therefore, the acknowledging of different colors and even its preference in one's culture can be influence by the traditional color systems enlightened by the origin about their color systems.

Regarding analysis of Chinese color system and its cultural preference on their costumes, there are some relating researches for extracting common factors about Chinese traditional colors and its images. Kim (2009) researched symbolism of colors, general characteristic of colors and cultural preferences influenced by geographic factor, internal factor and external one. And it suggests the color of costumes was decided by

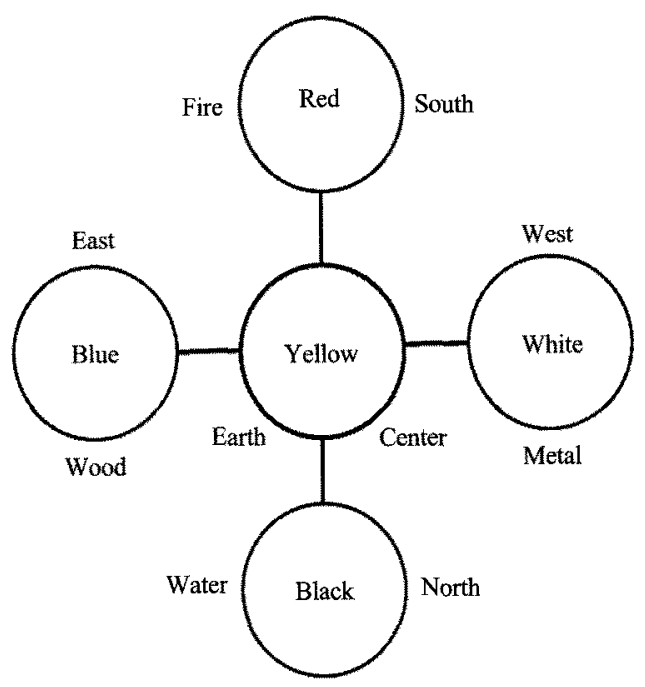

Fig. 1. The Eastern color systems from Yin-Yang theory. 


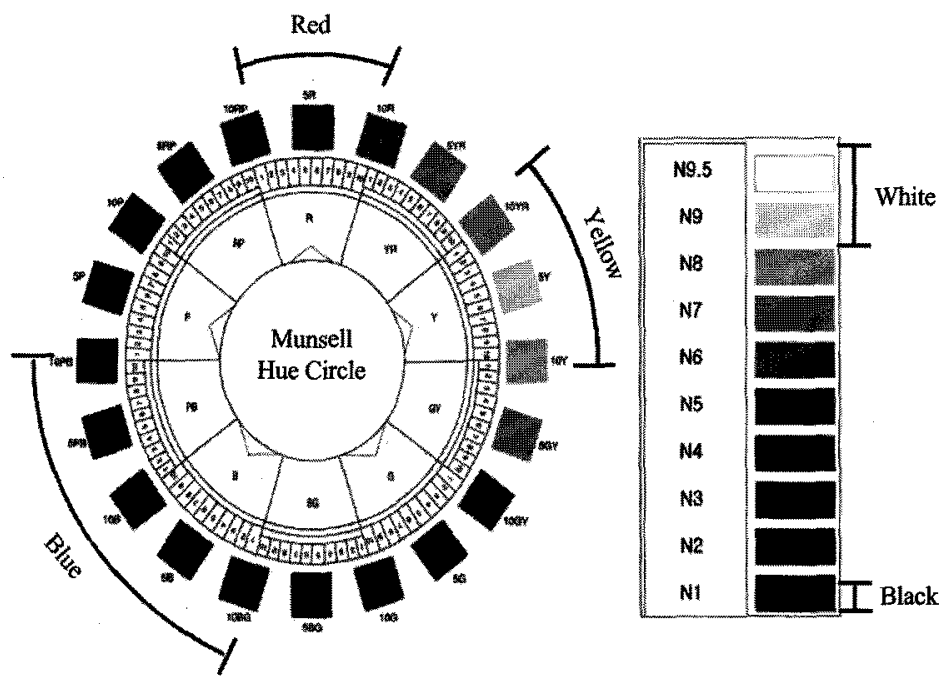

Fig. 2. The range of primer colors on the Western color systems for comparing to the Eastern color systems from Munsell Hue Circle, I.R.I Hue and Tone 120 System.

five colors relating five kinds of status. Kang (2008) states symbolism of colors, general characteristic of colors, cultural preference and words of colors affected by natural environment, national deposition, and so forth. Lee (2007) and Koo (2010) also says sociality and social customs as a criteria of color preference. In addition, in China, it was developed chromatic colors such as red, yellow and blue because of changing climates and yellow dust as well as religion such as Taoism, Buddhism and Confucianism. This table categorizes relating articles above and arranges specific particulars regarding Chinese traditional color system and the color of costumes (Table 1).

For more specific cultural meaning about five colors, $<$ Table $2>$ represents categorizing Chinese traditional colors and cultural meaning adding to the above concept. Five elements in the Chinese system of nature symbols is associated with a particular color or set of colors as well as with certain shapes, materials, designs and so forth. And it figures out Chinese traditional color's image divided into five elementsgold is included in Yellow color-and symbolic meaning for their cultural preference (Table 2).

\section{Methods}

This research was directly performed by field re- searching in Hong Kong and Beijing of China, from June to September, 2009. It is researched from the investigation of domestic and foreign references, visual materials such as DVDs, posters, the photos of specific scenes in related films, books, magazines, publication catalogue, archive newsletter and journals which identify concerning theories. More specific information regarding the Chinese costumes and color images in this article, it is also referred to primary sources through directly visiting Hong Kong Film Archive in HK, Costume Exhibitions of The China's New National Theatre in Beijing, and famous performing art shows such as Kung Fu performance in Mainland of China.

Concerning fundamental theory of colors, according to Kim and Lee (2006), first it defines Chinese traditional main colors based on Eastern color system which is explained five elements color Red, Yellow, Blue, White and Black from Yin-Yang theory. As Kim and Lee (2006) suggests, the color system developed from China's Yin-Yang theory focuses on the standard colors of five elements, Red, Yellow, Blue, White and Black. Second, the costumes of Chinese movie which are influenced by their traditional color images and cultural preference simultaneously identify how culture and costumes represented their traditional color's image in movies. Beyond these phases, it can be explained the traditional color's image and cultural pref- 
Table 1. The extracting list of Chinese traditional color systems and color preferences based on color symbolisms on costumes

\begin{tabular}{|c|c|c|c|c|}
\hline Study Items & $\begin{array}{c}\text { Kim }(2009), \\
\text { Kim \& Kim (2009) }\end{array}$ & Kang (2008) & Lee (2007) & Koo $(2010)$ \\
\hline $\begin{array}{l}\text { The Criteria } \\
\text { of Color Preference }\end{array}$ & $\begin{array}{l}\text { Geographic Factor } \\
\text { Internal Factor, } \\
\text { External Factor }\end{array}$ & $\begin{array}{l}\text { Natural Environment, } \\
\text { National Disposition } \\
\text { and Thought }\end{array}$ & $\begin{array}{l}\text { Sociality, } \\
\text { Individual Spirit } \\
\text { and Culture }\end{array}$ & $\begin{array}{l}\text { Social Background, } \\
\text { The Change of } \\
\text { Social Customs, } \\
\text { The Influence of } \\
\text { Foreign Culture }\end{array}$ \\
\hline \multirow{5}{*}{$\begin{array}{l}\text { The Symbolism } \\
\text { of Colors }\end{array}$} & Red: Wealth & $\begin{array}{l}\text { Red: Bright, Start, Noble, } \\
\text { Yang }\end{array}$ & $\begin{array}{l}\text { Red: Blood, Passionate, } \\
\text { Happy, Appetite }\end{array}$ & \multirow{5}{*}{$\mathrm{N} / \mathrm{A}$} \\
\hline & Yellow: Center, Emperor & $\begin{array}{l}\text { Yellow: Center, Emperor, } \\
\text { Prosperous }\end{array}$ & Yellow: Noble, Dignity & \\
\hline & Blue: Youth, Birth & $\begin{array}{l}\text { Blue: Youth, Law Status, } \\
\text { Birth }\end{array}$ & Blue: Youth, hope, Safety & \\
\hline & $\begin{array}{l}\text { White: Righteous, Pure, } \\
\text { Royalty }\end{array}$ & White, Pure, Sacred, Lucky & White: Pure, Bright, Clean & \\
\hline & Black: Authority, Official & $\begin{array}{l}\text { Black: Water, Memorial } \\
\text { Service, Official }\end{array}$ & $\begin{array}{l}\text { Black: Authority, Official, } \\
\text { Rigidity }\end{array}$ & \\
\hline $\begin{array}{c}\text { General Characteristics } \\
\text { of Color }\end{array}$ & $\begin{array}{l}\text { The Preference of Strong } \\
\text { and Vivid Color } \\
\text { The Frequent Use of } \\
\text { Chromatic Colors } \\
\text { Diverse Images Regarding } \\
\text { Colors }\end{array}$ & $\begin{array}{l}\text { Colors are Regarded as } \\
\text { Holy Things } \\
\text { The Symbolic Meaning } \\
\text { of Five Elements Colors } \\
\text { Represents Status of Palace } \\
\text { The Use of Red is } \\
\text { Expressed on the } \\
\text { Costumes of Queen }\end{array}$ & $\mathrm{N} / \mathrm{A}$ & $\begin{array}{l}\text { Five Elements Color is } \\
\text { Based on Color System } \\
\text { Five Elements Color } \\
\text { Means Universality and } \\
\text { Safety }\end{array}$ \\
\hline $\begin{array}{c}\text { Color and its Cultural } \\
\text { Preference }\end{array}$ & $\begin{array}{l}\text { Frequent Use of Red and } \\
\text { Blue } \\
\text { The Rare Use of Green } \\
\text { Red>Yellow>Black }\end{array}$ & $\begin{array}{l}\text { Predominant Use of Red } \\
\text { and Yellow }\end{array}$ & $\begin{array}{l}\text { Frequent Use of Chromatic } \\
\text { Colors } \\
\text { The Rare Use of White }\end{array}$ & $\begin{array}{l}\text { Red and Yellow>Blue> } \\
\text { Black and White }\end{array}$ \\
\hline Words of Colors & $\mathrm{N} / \mathrm{A}$ & $\begin{array}{l}\text { Yellow: 黃 } \\
\text { Red: 紅, 紫 } \\
\text { Blue: 藍, 紺, 紺靑 }\end{array}$ & $\begin{array}{l}\text { Yellow: 金, 黃 } \\
\text { Blue: 青天, 靑山 } \\
\text { White: 白鶴, 白虎 } \\
\text { Black: 黑客, 黑市 }\end{array}$ & $\begin{array}{l}\text { Red: 赤, 丹, } \\
\text { Black: 黑, 玄, 塉 } \\
\text { White: 白苗 }\end{array}$ \\
\hline
\end{tabular}

Table 2. Chinese traditional colors and cultural meaning, visual color symbolism chart by culture 'What different colors mean in different cultures'

\begin{tabular}{c|l}
\hline \hline $\begin{array}{c}\text { Color } \\
\text { Red }\end{array}$ & \multicolumn{1}{c}{ Cultural Meaning } \\
\hline Gold Yellow & $\begin{array}{l}\text { God Consciousness, Yang, Wealth, Strength, Metal Nourishing, Royalty, Proof against Evil, for the Dead, } \\
\text { Sacred, Imperial Yang, Earth, Auspicious, Sun Beans, Warmth, Motion }\end{array}$ \\
\hline Blue & $\begin{array}{l}\text { Immortality, Wealth, Self-Cultivation Yin, Wood, Calm, Healing, Relaxing, Peace, Trust, Adventure, } \\
\text { Exploration }\end{array}$ \\
\hline White & $\begin{array}{l}\text { Death, Mourning, Funerals, Helpful People, Children, Marriage, Mourning, Peace, Travel, Yang, Metal, } \\
\text { Death, Mourning, Spirits, Ghosts, Poise, Confidence }\end{array}$ \\
\hline Black & $\begin{array}{l}\text { Color for Young Boys, Career, Evil, Knowledge, Mourning, Penances, Yin, Water, Money, Income, } \\
\text { Success, Emotional Protection, Power, Stability, Bruises, Evil }\end{array}$ \\
\hline
\end{tabular}

From Kyrnin. (2010), http://webdesign.about.com/od/colorcharts/l/bl_colorculture.htm 
erence through the costumes of $<$ The Last Emperor $>$ (1987). The above concept is used to analyze the costumes with scenes as well as researched in the related imagery captured on film in $<$ The Last Emperor $>$.

\section{The Image of Chinese Traditional Color and Cultural Preference}

\section{Chinese Traditional Colors}

In China, throughout the years, and even today, colors are very important to the existence of the Chinese people. Thus, in terms of the color's images and cultural preference in the China, it needs to figure out symbolic meanings of color from historical theories and perceptions. Also symbolism and Images of colors varies from culture to culture (Chiazzari, 1998). That is to say, Chinese also have thought that color is associated with religious and spiritual meanings in their traditional cultures. As it mentions above, the standard colors of five elements in China, Red, Yellow, Blue, White and Black suggest or affect meanings to objects linked to specific concept or existence. That is, the Chinese traditional color and culture connotes symbolic meaning and conceptual idea in them. Specifically, Black means 'Water' in terms of YinYang theory and five elements (Kim, 2009). But people do not regard the color of water as a black, virtually. Chinese color system and each meaning of colors, however, shows that the symbolic meaning of water is deeply related the symbolic meaning of Black color. In chinese culture, the symbolic meaning of water can be explained 'Sorrow' and 'alienation' (Jo, 2010). Thus, they delineate these meaning with black in their culture as well as their life. Also, in terms of costumes in China, people strictly use divided colors according to symbolic meaning and class distintion by confucianism (Kim, 2009). Following section mostly covers the meaning of Chinese traditional colors regarding the Eastern color system as well as identifies cultural preference displaying through color's images and its symbolic meaning which is melted into Chinese life and culture.

\section{Chinese Traditional Colors and Cultural Pre- ference}

\section{1) Red Image}

Red color is particularly so called representative color of Chinese and it appeals authentic life and philosophy in China for a long time. This color can be understood the Chinese traditions and cultural identity through the symbolic meaning that the red implies. Today fire red is the most popular color and is thought of when thinking of China. It is better known today to symbolize happiness during holiday seasons. In terms of the Chinese beliefs regarding color, from ancient China, the red was not even recognized as being something special because it was the symbolic color of the Communist takeover of China. During those years, it held the symbol of blood and radical actions caused by the Communist parties (Bobo (Producer) \& NTDTV Broadcasting Service (Production), 2006). It is thus interesting to note that the Chinese still today, after the years of Communist actions, that red is used for some of the happiest moments in life, births, holidays and so on. According to Ho (1986), it figures out Chinese wedding closely relates red color in terms of ancient wedding traditions and cultural customs influencing even today's celebrations. The red plays a key role in the wedding and it is considered as lucky color, prosperity and happiness. That is the reason why the red is forbidden at funerals as it is a traditionally symbolic color of happiness (Fig. 3)-(Fig. 4)

As Gong (2005) mentions that after the Ming Dynasty, only the Emperor's close relatives could have homes with red walls and yellow roof tiles. Red is still used for happiness and joy. Thus, today red becomes one of the most well known colors in China. In the same line, it also finds out the use of red color from rituals and one's life style. A sketch of Soong Ching Ling and her Artifacts is the display of her private and historical collection which shows Chinese women of upper class to enhance the public understanding of this remarkable lady of the $20^{\text {th }}$ century in China ("Material culture of Shanghai", 2009). Soong Ching Ling (1893-1981) was Dr. Sun Yat-sen's wife and the honorary President of the people's republic of 


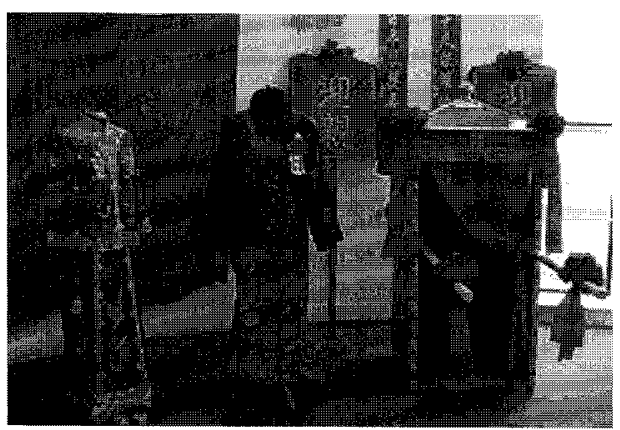

Fig. 3. Formal Chinese wedding.

from Lee. (2005). http://chinatownconnection.com/chinese marriage.htm

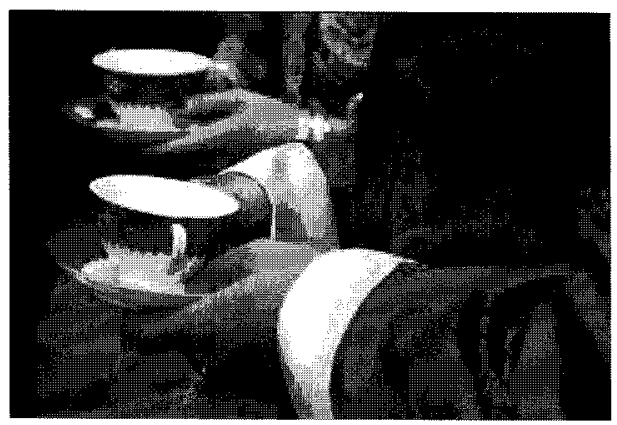

Fig. 4. Chinese weddings embrace.

from Reggie. (2009). http://bellapictures.com/planning/chinesewedding-tradition

China, and her legendary life was inextricably intertwined with China's history in the past one hundred years. These valuable exhibits, including a wedding gift from Soong Ching Ling's mother and many of items on display come from her collection (Fig. 5).

Regarding cultural preference regarding advertisements in China, $\mathrm{Li}$ (2002) says that red color can't be absent. According to Chinese view, red color represents energy, enthusiasm, happiness and good luck relating Feng Shui theory. The frequency of its appearance in advertising is much higher than other color. For example, in the serial advertising of “杉品牌”, a sort of red color marketing, the red flag serves as the background. Red color guides the scenes, which appropriately symbolize its business spirit forging ahead, pioneering and regarding human being as the center (Fig. 6).

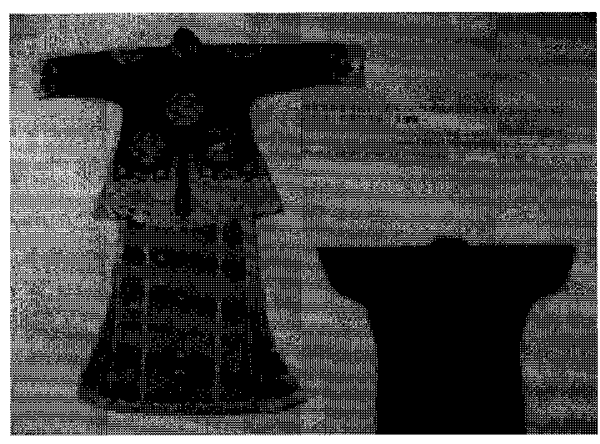

Fig. 5. Soong Ching Ling's wedding collection. from "Material culture of Shanghai". (2009). p. 39.

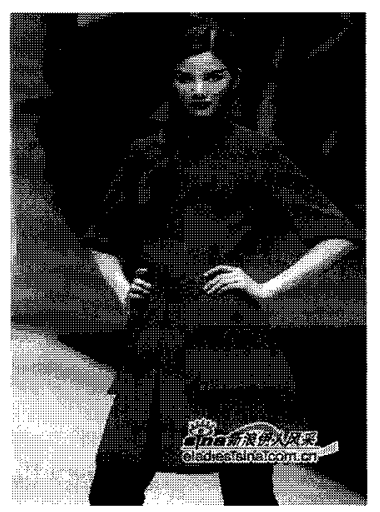

Fig. 6. Advertising of “杉品牌”, Red color marketing. from Wang. (2007). http://eladies.sina.com.cn/fa/2007/0319/ 1933413494.html

\section{2) Yellow Image}

Yellow is also seen as a good luck color like red, as it is sometimes paired with red in place of gold, for obvious reasons. It was the representative color of the robes and attire of the emperors. Hua (2005) mentions that yellow color has a special role in Chinese culture. It is the symbol of nobility and royalty in ancient time. As yellow is still reserved for royalty in cultural preference, clothing and objects in yellow still resemble a higher social status. Thus, many films and other media reflecting Chinese history show this color in king's costume mainly. Also the symbolic meanings in Chinese traditional costumes melted into each character's costumes relating the color coordination and its arrangement with Yin-Yang theory ("When film", 2009). For concrete instance, gold color close to yellow is represented an emperor, so it usu- 


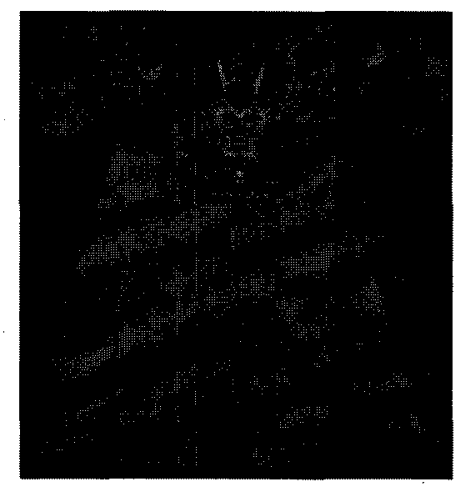

Fig. 7. The yellow silk fabric, material for court robe, reign of Wanli emperor (1573-1619).

from Palace Museum Beijing, (2008). http $/ /$ marinmaven.webjaw.com/culture-maven-ming-show-at-asian-art-museum/

ally see this color in the king's costumes on movies because Chinese traditionally regard the gold as the sun. $<$ Fig. $7>$ represents the costume of.Wanli emperor (1573-1619). At Palace Museum in Beijing, this treasure was packed away for four centuries during the reign of the Wanli and discovered in its original box in storage at the Museum. This yellow hue was reserved for the emperor and empress as was the five-clawed dragon. Although each dynasty designates each official rank with their own color, yellow is reserved for the emperor himself. However, It is also the main color of Buddhism; thus it represents being free from worldly cares. Particularly, yellow is used as a mourning color for Chinese Buddhists, in case of deceased monks. According to the China Heaven Creation International Performing Arts Co., Ltd. (Production) (2009), in china, yellow was described as a holy and inviolable meaning in monk costume (Fig. 8).

\section{3) Blue Image}

Blue color is a symbol of spring when everything is filled with health, prosperity and peace. Bobo (Producer) and NTDTV Broadcasting Service (Production) (2006) states blue is associated with "immortality, health, prosperity, peace, relaxing and harmony." Therefore, someone that is hoping for longevity and harmony will decorate with blue colors. $\langle$ Fig. $9>$ describes blue dragon sculpture in China Garden and it symbolizes immortality, vigor and vitality. Kim and Lee (2006)

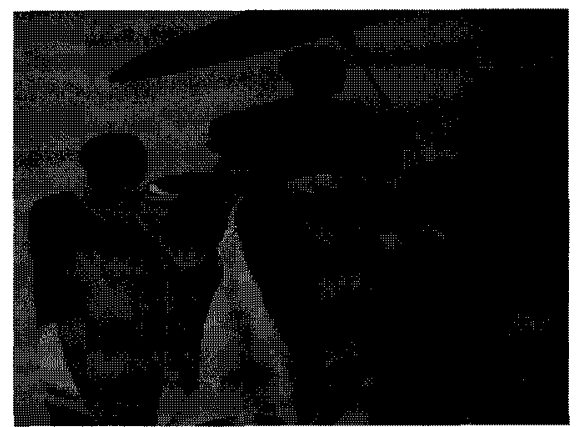

Fig. 8. Buddha monk painting.

from Jawa Quality Furniture. (2009). http://www.jawa.com.aw ecom/product $/ 3683$ /buddha-monk-painting-m-1m-x-1.2m

says blue is usually utilized in Chinese traditional costumes especially purple blue relating decorative traits of the cultural tradition. Therefore, it figures out that color of blue level stabilized in cultural preference as its images and ideological concept. Also, it can be easily found out the typography or other graphic signs in blue color which is symbolized life and prosperity in many areas of China (Fig. 10).

\section{4) White Image}

White is still a symbol of the unknown and purity in China. And it is also the color of mourning, death, and ghosts. Thus, Chinese people usually wear white during a funeral or while summoning ghosts. They mainly consider black is the beginning and white is the end $(\mathrm{Li}, 2002)$. So, white is known for purity or brightness and is used at times of mourning. Just unlikely the western meanings of purity, chastity, holiness and cleanliness, white are associated with death, and it is used predominantly in funerals in Chinese culture. According to English.eastday.com (2010), concerning Chinese Funeral Customs, when a death occurs in a family all statues of deities in the house, a white cloth is hung over the doorway to the house and a gong is placed to the left of the entrance if the deceased is a male, and to the right if female (Fig. 11). In the Chinese movie < Farewell My Concubine> (1993), the white color used as the meaning concerning death and calm which means a sort of hint somewhat developing dynamic situation relating (Xu, 1997) (Fig. 12). 


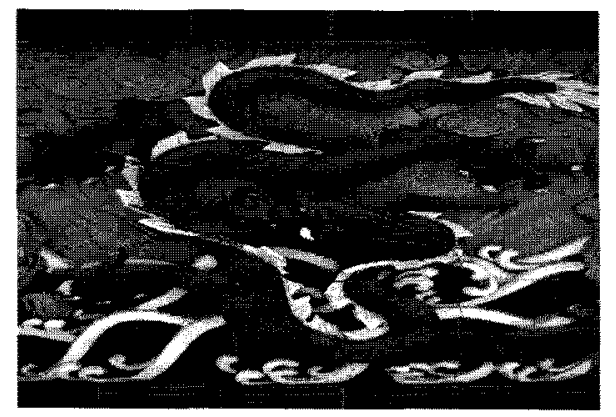

Fig. 9. Blue dragon in the China garden (St. Petersburg).

from Lvova. (2008). http://commons.wikimedia.org/wiki/File: Blue_china_dragon.jpg

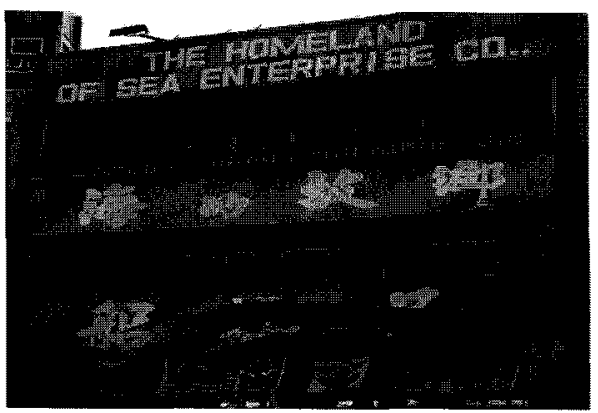

Fig. 10. Chinese typography in Blue. homeland of sea, Kaohsiung.

from Sinha. (2009). http:/gemismyname.com/tag/chinese-characters/page/2/

\section{5) Black Image}

Black is a neutral color used in daily clothing but is also used during a funeral to symbolize mouming, possibly adopted from western practices. Hua (2005) mentions, a black ribbon is usually hung over the deceased's picture. Black is still used as the symbol of winter and the westerly skies which behold the heavens (Jo, 2010). It is used for times of the unknown and for the winter months. However, in terms of colors preference in China, black and gold indicate luxury while bright, multi-colored packages connote fun, such as snack foods or candy in spite of that black is seriously considered as a color of mourning as well as a color of respect and dignity.

The most distinctive is that black color in history of china is different from other nations such as Korea and Japan. Black has been used for the color of offi-

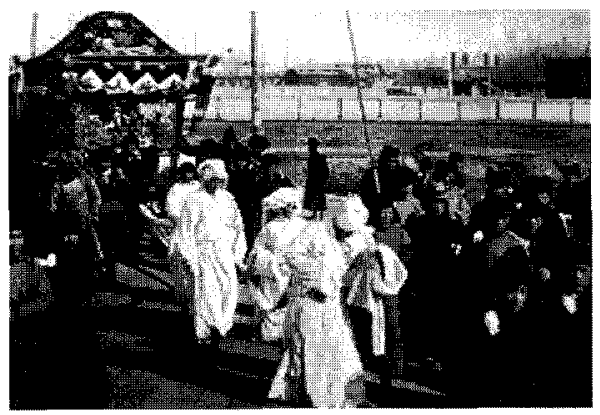

Fig. 11. Chinese funeral customs.

from English.eastday.com. (2010). http:/english.eastday.com/e/ cosh/ula4173005.html

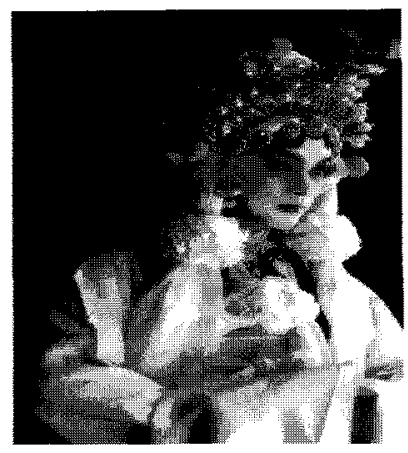

Fig. 12. Leslie Cheung in <Farewell My Concubine> (1993).

from Vicki. (2008). http//vickiblog.wordpress.com/2008/01/10/ topfiveocrossdressingactors/

cial uniform in China. The aspect of black concerning perception and history can be found from Jin Dynasty of China which was united six-nations by the Qin Shi Huang. The representative color of nation was indicated in black, and it has applied to official uniforms from that time. After few decades, black uniform is used with red one based on Yin-Yang theory (Gong, 2005). That is the reason why people usually can see the black official uniform in traditional movie, drama or magazines in China (Fig. 13). Besides, Chinese have the perception about black relating death. In case of customs and traditions before death, upon the death of a loved one the body and casket must be prepared for the wake and funeral. The body is first washed and powdered and is dressed in his or her favorite or best outfit. The color of the clothing is usually dark blue, particularly black (Fig. 14). 


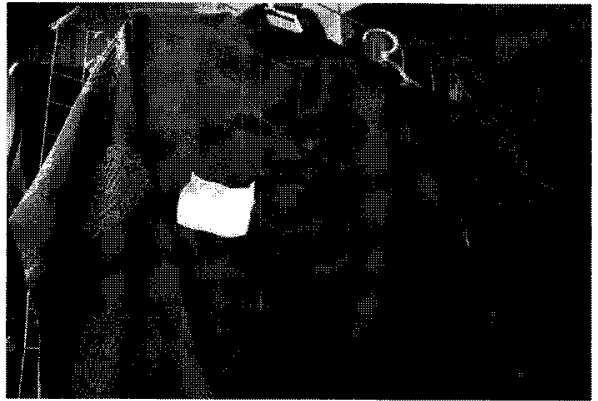

Fig. 13. "Shou Yi", Funeral clothes. from Jenn. (2009). http://blog.asiahotels.com/2009/09/

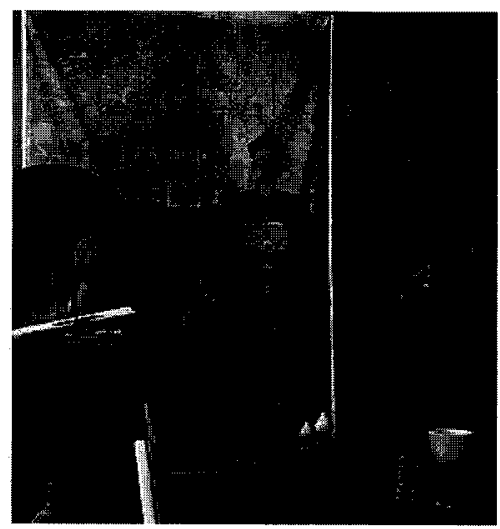

Fig. 14. The minister wearing black costume in Furniture Decoration of Chinese Style.

from Design.Co.Kr. (2008). http//luxury.design.co.kr/in_magazine/ sub.htm

\section{Traditional Color and Cultural Preference on <The Last Emperor>}

In media such as films, the use of color and costumes has important meaning and give an impression to represent the culture of one's society. The five element form of Feng Shui classifies various aspects of color and design according to their relationship to the predominant forces in nature by analyzing colors in media and surroundings with the five elements and their color meanings. The issue is that color expressions of movies in China have variety of traditional color and cultural preference and they are melted into the scene. <The Last Emperor > is the film detailed production and costume design, and this research is based on director's cut and comments. In addition, it refers to the thesis of function of colors as a meaning carrier in the movies (Bang, 2004).

\section{Red Image}

In $<$ The Last Emperor $>$, red color is extensively used in almost the whole scene as it was stated the preference of red above. Particularly, red is enormously shown for the emperor's wedding ceremony scene which is symbolized the happiest moments in life. Also, it is reflected wedding traditions and cultural customs of Chinese dynasty influencing even today's cultural preference. The color scheme in which red predominates apparently represents in this movie (Fig. 15)-(Fig. 18). Moreover, red is also mainly shown in the scene of ceremonial walk of the emperor for daytime. It comes from the traditional values red has and the preference of using the images of vitality and energy (Fig. 19)-(Fig. 20).

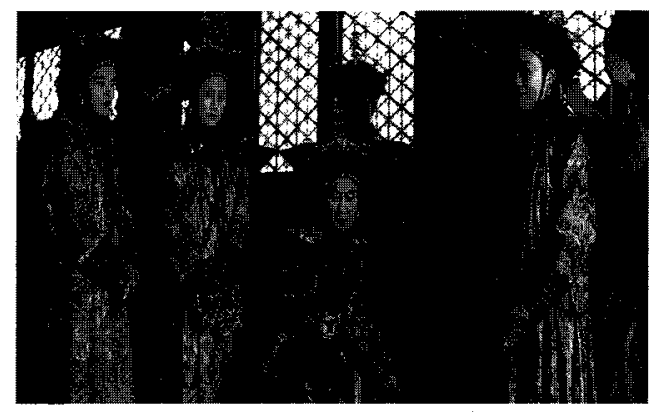

Fig. 15. The wedding of Emperor 1. from Thomas (Producer) \& Bertolucci (Director). (1987).

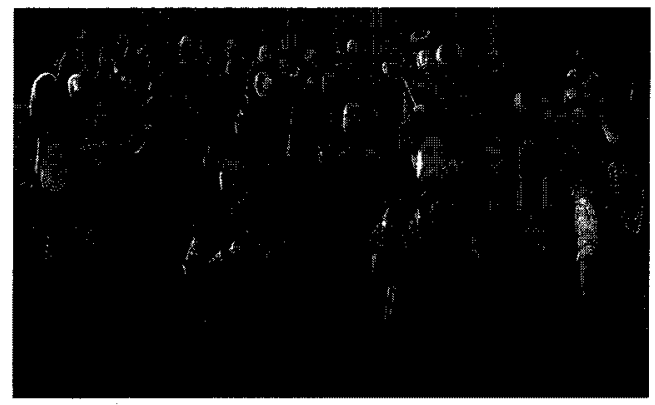

Fig. 16. The wedding of Emperor 2.

from Thomas (Producer) \& Bertolucci (Director). (1987). 


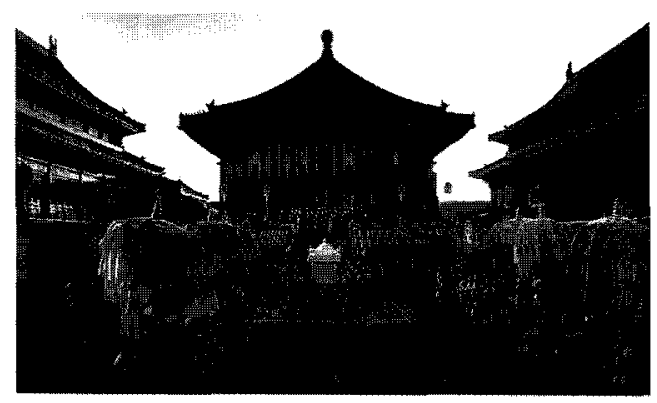

Fig. 17. The wedding of Emperor 3.

from Thomas (Producer) \& Bertolucci (Director). (1987).

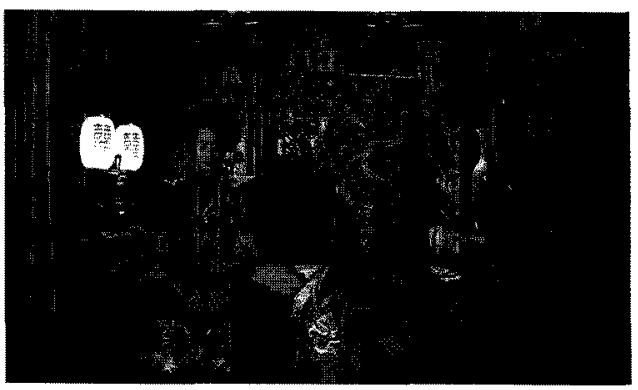

Fig. 18. The wedding of Emperor 4.

from Thomas (Producer) \& Bertolucci (Director). (1987).

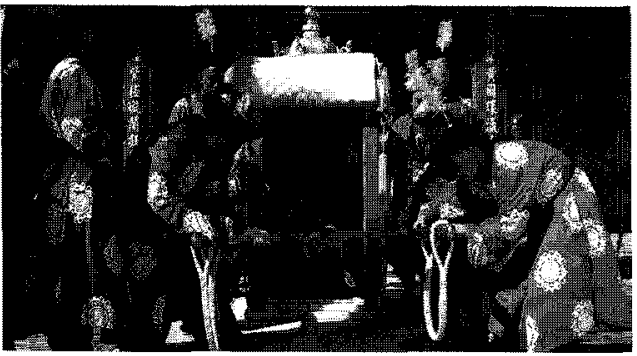

Fig. 19. The ceremonial walk of Emperor 1. from Thomas (Producer) \& Bertolucci (Director). (1987).

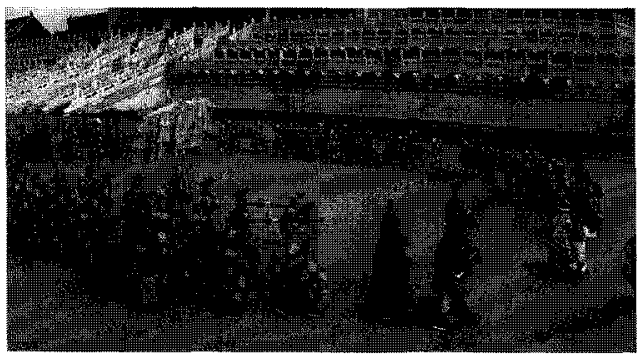

Fig. 20. The ceremonial walk of Emperor 2. from Thomas (Producer) \& Bertolucei (Director). (1987).

\section{Yellow Image}

In terms of the history about the emperor's color, the Yellow Emperor in China was named by the idea of the Feng Shui yellow earth. In the film, it delineates the life of Emperor Pu Yi in Forbidden City, who took the throne at age three as well as the emperor's traditional costume by using yellow color and gold decorative embroidery. At the movie poster, it clarifies the subject for symbolic image of Emperor through expressing yellow (Fig. 21)-(Fig. 22). It can be interpreted the traditional image of king who has absolute authority from the preference about yellow. Accord-

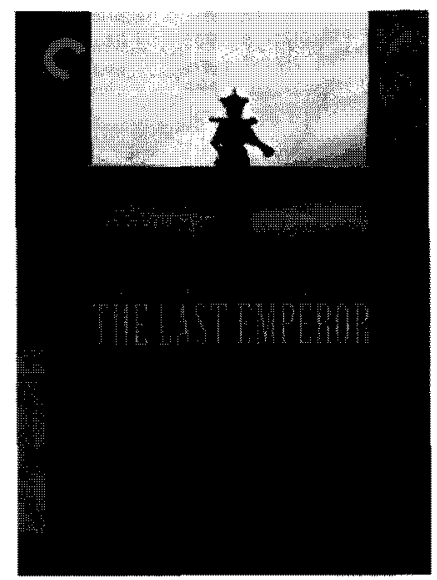

Fig. 21. The posters of <The Last Emperor> 1. from "When film". (2009). p. 5.

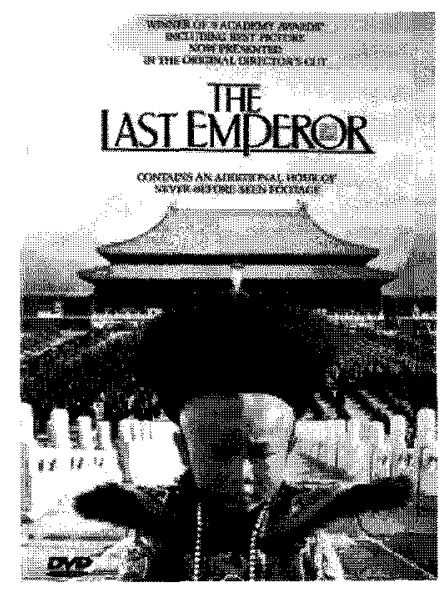

Fig. 22. The posters of <The Last Emperor 2. from "When film". (2009). p. 5. 


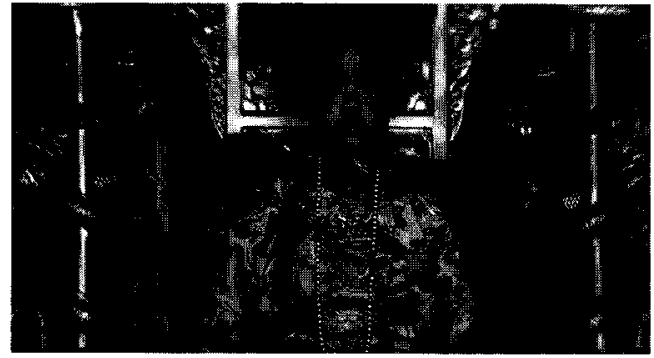

Fig. 23. The costumes of young Emperor 1. from Thomas (Producer) \& Bertolucci (Director). (1987).

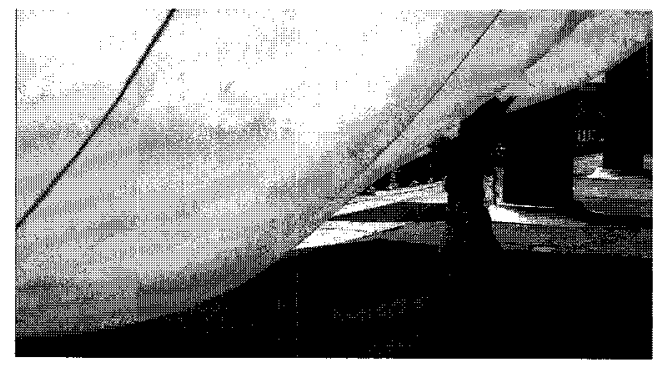

Fig. 24. The costumes of young Emperor 2.

from Thomas (Producer) \& Bertolucci (Director). (1987).

ing to Bang (2004), specifically in the scene which the power of emperor was predominant, the costumes of $\mathrm{Pu} \mathrm{Yi}$ are shown extremely splendid by yellowish color arrangement and mostly cover by yellow and gold (Fig. 23)-(Fig. 24). In the movie, Pu Yi scolds a common young boy about his wearing in yellow and tells him only king wears yellow clothes (Fig. 25). And the power of emperor gradually diminish over the time, the range of yellow is downscaled than the prior (Fig. 26).

\section{Blue Image}

In the movie of <The Last Emperor>, it shows the king's sleeves in decorative blue color which gives the symbolic meaning of vigor and immorality. Yellow and blue arrangement is usually described as a decorative purpose of point color in a collar and sleeves for visual aspect as well as the combination of Yin and Yang which is based on traditional color arrangement (Fig. 27)-(Fig. 28). The most distinctive is blue is rarely shown as a main color in the movie and, blue is somewhat expressed in a small

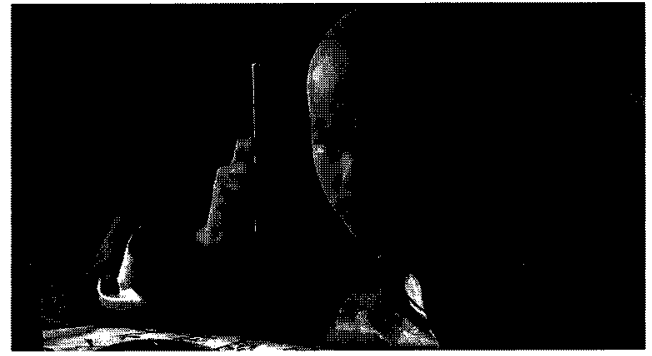

Fig. 25. A common boy wearing in yellow sleeves. from Thomas (Producer) \& Bertolucci (Director). (1987).

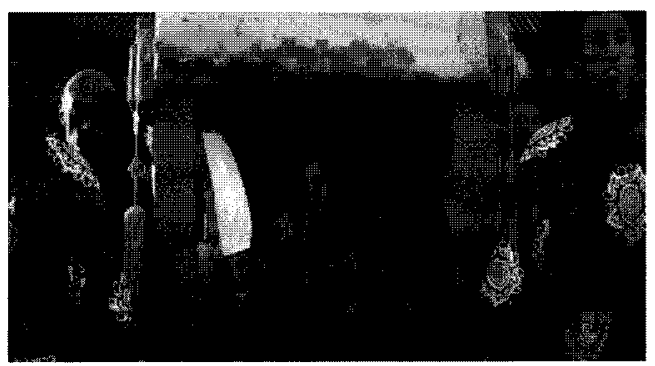

Fig. 26. Youth Emperor's costumes 1. from Thomas (Producer) \& Bertolucci (Director). (1987).

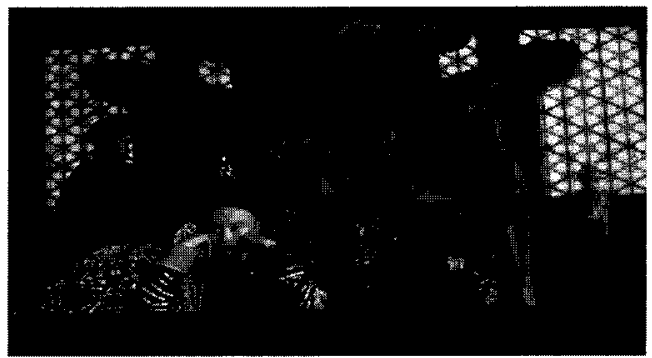

Fig. 27. Youth Emperor's costumes 2. from Thomas (Producer) \& Bertolucci (Director). (1987).

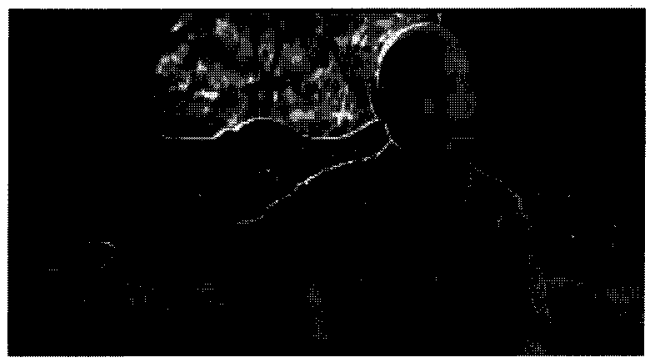

Fig. 28. Youth Emperor's costumes 3.

from Thomas (Producer) \& Bertolucci (Director). (1987).

portion for decoration or for an ordinary wear (Fig. 29)-(Fig. 30). Through this sort of color expres- 


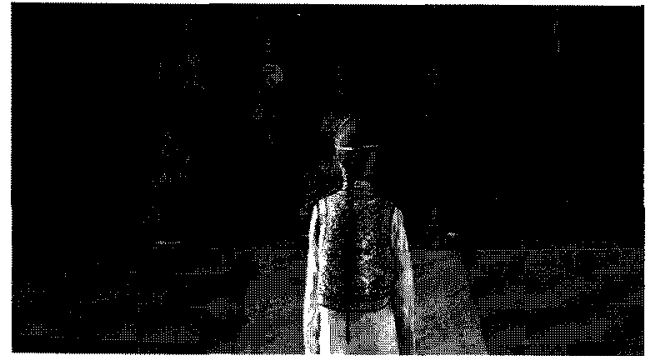

Fig. 29. Youth Emperor's costumes 4. from Thomas (Producer) \& Bertolucci (Director). (1987).

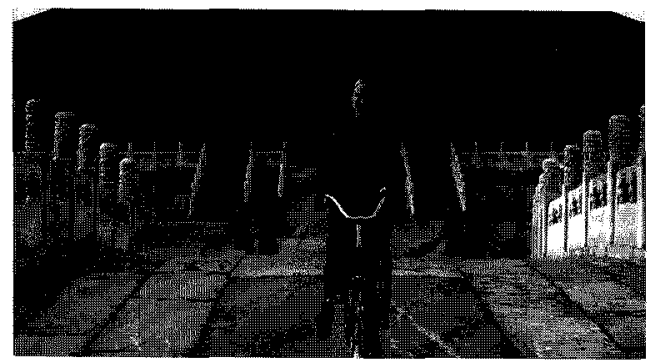

Fig. 30. Youth Emperor's costumes 5.

from Thomas (Producer) \& Bertolucci (Director), (1987).

sion, the preference of blue is relatively less effective than red and yellow in the movie. Thus, it figures out that traditional color image regarding emperor's costumes reduces blue in main color symbolizing Yin component.

\section{White Image}

White color is not relatively used for a main color or predominant one in <The Last Emperor>, but it is effectively described in this movie. It shows the connectivity between traditional color images and characteristics as well as the aspect of the application of color based on preference. For example, as the young emperor enters the palace for the first time, he is wearing white fur jacket and walking with his tiny feet toward the queen. And he usually wears white clothes and feels comfortable when he was young. The white color is well expressed his purity and image of child based on its traditional image comparing to his confusion and tough future (Fig. 31)-(Fig. 32). In the scene of dying the queen, a white cloth is covered her face as the signal of the death. The tradi-

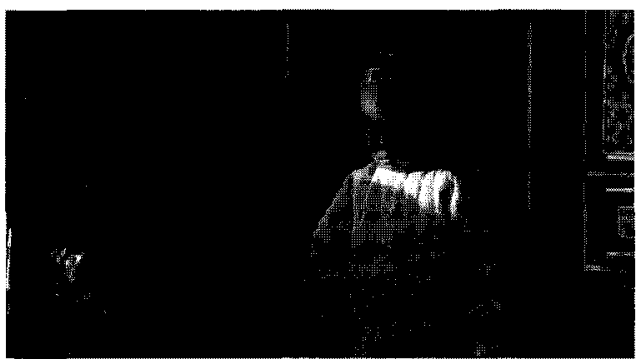

Fig. 31. The costumes of young Emperor 3. from Thomas (Producer) \& Bertolucci (Director). (1987).

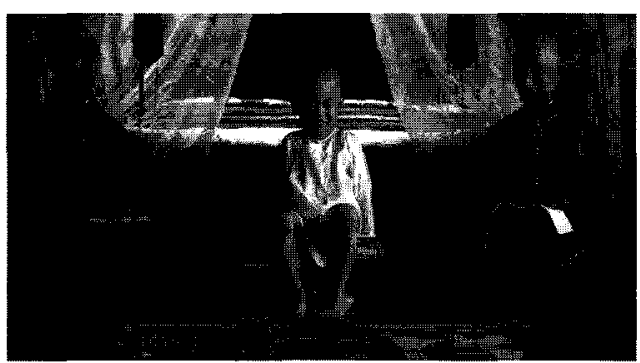

Fig. 32. The costumes of young Emperor 4. from Thomas (Producer) \& Bertolucci (Director). (1987).

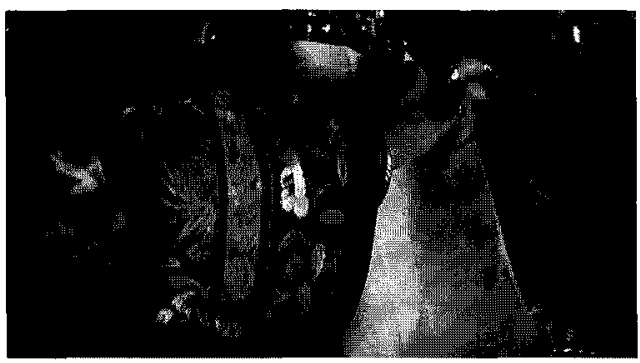

Fig. 33. The white cloth covered on queen's face. from Thomas (Producer) \& Bertolucci (Director). (1987).

tional image of white is drawn for death contrast to purity or cleanness (Fig. 33).

White is similarly recognized its traditional image and preference in Korea based on its two sides of images. In terms of using white in several scenes, it can be understood traditional images of white and the preference of its use through the movie.

\section{Black Image}

Exceptionally black color in this film is widely shown in most costumes. With red and yellow color, 
black is mainly used for the movie. It can be figured out that black is just not used for funeral or bad implication like Korean traditional costumes, but it is diversely utilized from ordinary wear to courtier's costumes and so forth. For instance, in terms of ordinary wear, western style suit of the foreign tutor and Chinese courtier's attire is both in black, but they are somewhat different for the image in the use of black (Fig. 34)-(Fig. 35). As black of courtier's costume is clearly contrasted to emperor's yellow, the distinction between king and courtier become clarify. Also courtiers sometimes wear black attires for night time carrying a palaffquin whereas they have red clothing for day (Fig. 36). In < The Last Emperor>, black color is used as ordinary attire of emperor, and it implies coldness and decisive mind with resolute attitude. And director, Bertolucci intended using bright colors such as reds, yellows, and oranges based on Chinese traditional colors and their preference to accentuate the traditional dress and lavish lifestyle of the young emperor ("When film", 2009). Contrarily, the outside

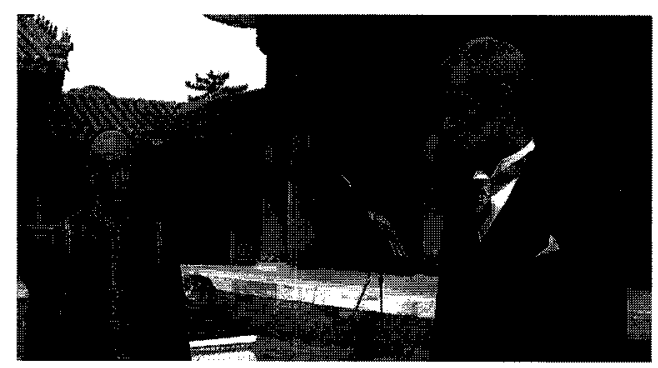

Fig. 34. The courtiers wearing in black for ordinary wear 1.

from Thomas (Producer) \& Bertolucci (Director). (1987).

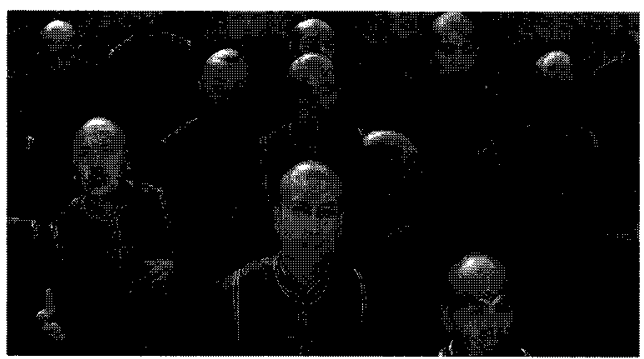

Fig. 35. The courtiers wearing in black for ordinary wear 2.

from Thomas (Producer) \& Bertolucci (Director). (1987).

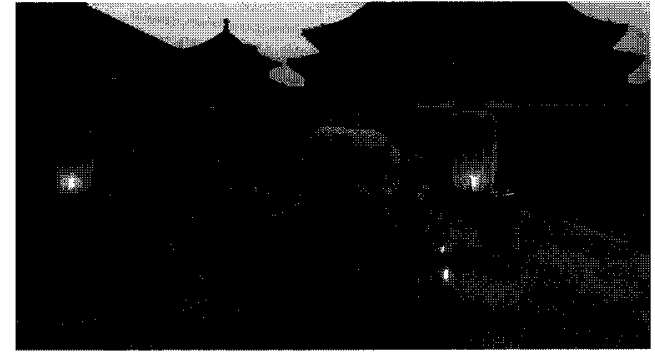

Fig. 36. The courtiers wearing in black for night time. from Thomas (Producer) \& Bertolucci (Director). (1987).

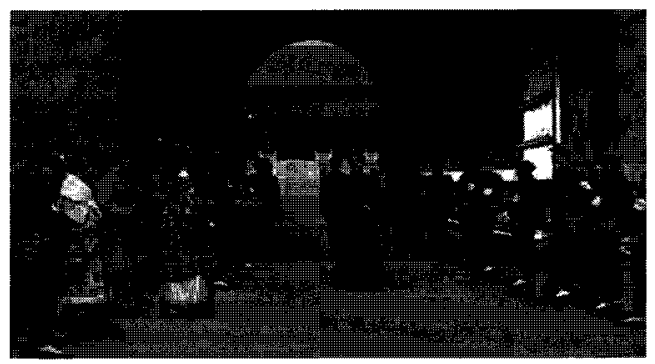

Fig. 37. The Emperor in black outside palace. from Thomas (Producer) \& Bertolucci (Director). (1987).

palace scenes of Pu Yi's later life make use of black tones and very simple as wearing the type of uniform (Fig. 37). After this time, the emperor in several scenes relating historical changes is also influenced by western culture and color symbolisms.

\section{Conclusions}

The results of this research can be summarized as follows.

First, the image of Chinese traditional colors represents in many parts of < The Last Emperor $>$, and cultural preferences also underlies their works through the expression of traditional color. It can be explained that the traditional costumes and colors through scenes express visual embodiments of the costumes reflecting specific status, ceremony or ritual such as the status of emperor, wedding, ordinary wear and so forth. It can be stated that these expression is also influenced by Chines cultural preference.

Specifically, Red predominates apparently represents in this movie. It is reflected traditions and cultural customs of Chinese dynasty influencing even 
today's cultural preference. Moreover, it comes from the traditional values red has and the preference of using the images of vitality and energy. The range of Yellow is almost same as red. It clarifies the subject for symbolic image of Emperor through expressing yellow. It can be interpreted the traditional image of king who has absolute authority from the preference about yellow. As the power of emperor was predominant, the costumes of king are shown extremely splendid by yellowish color arrangement and mostly cover by yellow and gold. In color expression, the preference of Blue is relatively less effective than red and yellow in the movie. Thus, it figures out that traditional color image regarding emperor's costumes reduces blue in main color symbolizing Yin component. White is not relatively used for a main color or predominant one in <The Last Emperor>, but it is effectively described in this movie. It precisely shows the connectivity between traditional color images and characteristics as well as the aspect of the application of color based on preference. Exceptionally black color in this film is widely shown in most costumes. With red and yellow color, black is mainly used for the movie. It can be figured out that black is just not used for funeral or bad implication like Korean traditional costumes, but it is diversely utilized from ordinary wear to courtier's costumes and so forth. As black of courtier's costume is clearly contrasted to emperor's yellow, the distinction between king and courtier become clarify.

Second, the traditional colors which were used in the movie are based on Yin-Yang theory. Particularly, Red, Yellow, Black is mostly used for the costumes. That is, it can be understood these colors are not only used for royal family and people related palace, but these traditional colors are closely reflected the preference of Chinese people. The component of five elements influences to color arrangement in aspect of applying main colors to traditional costume in the movie.

Third, there are some differences the use of color's arrangement, somewhat changes regarding use of traditional color according to character's images and situations by director's intention. The most distinctive is blue is rarely shown as a main color in the movie and, blue is somewhat expressed in a small portion for decoration. Through this sort of color expression, the preference of blue is relatively less effective than red and yellow in the movie. Thus, it figures out that traditional color image regarding emperor's costumes reduces blue in main color symbolizing Yin component. That is, planning the color arrangement is considered engaging connectivity between tradition and images in movie, and it tends to extend or reduce based on character's images or situations by director's intention. Even though director's intentions and other situations are limited to the accurate expression of traditional colors, it can be conjectured that the core image and value of the color is inherent in the film.

Fourth, as the story of the movie is proceeding, the increase and decrease of color arrangement is distinctively represented. Particularly, the use of Red and Yellow which means blessing, happy days and Emperor's kingdom is gradually declined as the young emperor become adult, and he lose the king's power. On the contrary, the black is conspicuously increased as the monarchy is collapsed by Japan, and the time period changes to Modern.

In conclusion, color's image and cultural preferences represent red, yellow, blue, white and black reflects chinese traditional image with balance of Yin Yang Theory, but there are somewhat enlargement, reduction or changes of brightness in the range of color by directing situation. This sort of changes reflects time period and the proceeding of story, thus it represents that traditional color and cultural preference has an important role on the development of story.

This study is mostly researched based on the images of chinese traditional colors and cultural preference, and these components comparatively affect to many scenes and costumes. However, according to consider real aspects and styling factors, the use of color on movie costumes may set a limit by director's intention and story's development. Based on this research, it is expected comparative study between Chinese movie costumes and Korean one with the image of traditional color and color preference for future research.

\section{References}

Bang, K. R. (2004). A study on the function of colors as a 
meaning carrier in the movies-The film "The Last Emperor" was used as the main study material-. Korean Society of Basic Design \& Art, 5(2), 176.

Bobo. (Producer). \& NTDTV Broadcasting Service (Production). (2006, November 27). Chinese Culture: Five Elements and Five Colors, The Meaning of Colors in Ancient China [Motion picture]. Beijing: NTDTV Broadcasting Service.

Chevreul, M. E. (1967). The principles of harmony and contrast of colors and their applications to the arts. New York: Reinhold Publishing Corporation.

Chiazzari, S. (1998). The complete book of color. New York: Barnes and Noble Books.

China Heaven Creation International Performing Arts Co., Ltd. (Production). (2009, July 23). Chunyi the Legend of Kung Fu [Motion picture]. Beijing: Beijing Heaven Creation Global Kungfu Theatre Co., Ltd.

Design.Co.Kr. (2008, September 15). The Minister wearing black costume in furniture decoration of Chinese style. Culture and life style designer. Retrieved October 10, 2010, from http://luxury.design.co.kr/in_magazine/sub. htm

English.eastday.com. (2010, October 16). Chinese funeral customs. Chinese American portal. Retrieved October 22, 2010, from http://english.eastday.com/e/cosh/ula4173005. html

Gong, R. (2005). Good luck life: The essential guide to Chinese American celebrations and culture. New York: Harper Paperbacks.

Ho, H. W. (1986). Local traditional Chinese wedding. Hong Kong: Hong Kong Museum of History Urban Council Friendship Printing Co, Ltd.

Hua, F. (2005). A contrastive study on cultural connotations of basic color terms between English and Chinese. Jilin: Jilin University.

Jawa Quality Furniture. (2009). Buddha monk painting. Chinese furniture and painting. Retrieved October 22, 2009 , from http:/www.jawa.com.au/ecom/product/3683/buddha-monk-painting

Jenn, G. (2009, September 9). "Shou Yi", Funeral clothes. Asian culture and social customs. Retrieved October 22, 2009, from http://blog.asiahotels.com/2009/09/

Jo, K. R. (2010, March 22). Column about the traditional colors. National online. Retrieved December 1, 2010, from http://okfashion.co.kr/index

Kang, M. J. (2008) The color analysis of the traditional alcoholic beverage package design of Korea and China with an oriental spirit (negative, positive and five primary substances). Journal of Korean Society of Communication Design, 11, 1-11.

Kim, J. E. (2009) Color characteristics of the costumes of Beijing opera. Journal of the Korean Society of Costume, 59(2), 143-153.
Kim, J. E., \& Kim. J. Y. (2009). A study on the attributes of cultural color in Korea and China-Focus on traditional performance-. Journal of the Korean Society of Costume, 33(3), 457-466.

Kim, Y. I., \& Lee, J. H. (2006). A comparative study on the characteristics of traditional costume colors of Korea China-Japan. Journal of the Korean Society of Costume, 56(8), 36.

Kim, Y. S., \& Kim, J. H. (2010). A study on stage costume using traditional Hanji-Focused on theatre 'Long Long Time Ago Whuo-ee Whuo-ee'-. Journal of the Korean Society of Costume, 34(2), 338.

Koo, K. M. (2010). A study on the Chinese words of colours. Journal of Formative Art and Media, 13(3), 15-20.

Kyrnin, J. (2010). Visual color symbolism chart by culture. What different colors mean in different cultures. Retrieved October 22, 2010, from http://webdesign.about. com/od/colorcharts/l/bl_colorculture.htm

Lee, K. H. (2007). Study on emotional coloring of the Chinese which is reflected to color terms. Journal of Chinese linguistics, 24, 535-556.

Lee, W. Y. (2005). Formal Chinese wedding. Houston chinatown portal. Retrieved October 2, 2009, from http:// chinatownconnection.com/chinese marriage.htm

Li, Z. (2002). Cultural differences between China and western countries: A comparison study from the perspective of advertisement. Unpublished master dissertation, Peking University, Beijing.

Lvova, A. (2008, March 23). Blue dragon in the China garden (St. Petersburg). Blue China dragon. Retrieved September 22, 2010, from http://commons.wikimedia.org/ wiki/File:Blue_china_dragon.jpg

Ma, E. K. W. (1999). Culture, politics, and television in Hong Kong. London: Routledge.

Material culture of Shanghai and Hong Kong. (2009). Hong Kong Museum of history Newsletter (April to June), p. 39.

Palace Museum Beijing. (2008, September 22). The yellow silk fabric, material for court robe, reign of Wanli emperor (1573-1619). Asian art museum. Retrieved October 10, 2009, from http://marinmaven.webjaw.com/ culture-maven-ming-show-at-asianart-museum/

Pieterse, J. N. (2004). Globalization and culture: Three paradigms. Lanham, MD: Rowan \& Littlefield Publishers, Inc.

Reggie, D. (2009, October 10). Chinese weddings embrace. Chinese weddings. Retrieved October 22, 2009, from http://www.bellapictures.com/planning/chinese-weddingtraditions

Sinha, S. (2009, April 22). Chinese typography in Blue. Homeland of sea, Kaohsiung. Retrieved October 25, 2010, from http:/gemismyname.com/tag/chinese-characters/page/2/ 
Sloane, P. (1989). The visual nature of color. Blue Ridge Summit, PA: TAB Books.

Thomas, J. (Producer), \& Bertolucci, B. (Director). (1987, November 18). The Last Emperor [Film]. Los Angeles: Columbia Pictures.

Timmy, Y. (2008, November). Illusions of silence and passage. Common Wealth Magazine, p. 22.

Vicki. (2008, January 10). Leslie Cheung in $<$ Farewell My Concubine (1993)>. Top five of cross dressing actors. Retrieved October 22, 2009, from http://vickiblog.wordpress.com/2008/01/10/topfive-of-cross-dressing-actors/
Wang, J. Q. (2007, March 19). Advertising of “杉品牌”, Red color marketing. SINA Corporation. Retrieved October 2, 2009, from http://eladies.sina.com.cn/fa/2007/ 0319/1933413494.html

When film and Chinese opera meet. (2009, November 2). Collective memories in Movies Posters of Hong Kong Film Archive Publication Catalogue, p. 5.

Xu, B. (1997, July). Farewell my concubine and its Western and Chinese viewers. Quarterly Review of Film and Television, 16, p. 2. 